\title{
Reduced in-hospital mortality from acute myocardial infarction with general adoption of thrombolytic treatment in the North West Thames health region* 1979-1991
}

\author{
R A Greenbaum, R Morris, P Sritara, D Shanit, K L Chan
}

\begin{abstract}
Objective-To determine the impact of studies of thrombolytic treatment in acute myocardial infarction on inhospital mortality.

Design-Retrospective study.

Setting-All 21 major hospitals in the North West Thames health region.

Patients-63903 patients with acute myocardial infarction.

Study period-1979-1991.

Main outcome measures-in-hospital mortality.

Results-Overall mortality decreased by $5.2 \%$ from $25.4 \%$ to $20.2 \%$ (P $<0.0001)$ (95\% confidence interval (CI) $3 \cdot 4$ to $6 \cdot 6$ ). Male mortality decreased by $6.5 \%$ from $22.3 \%$ to $15.8 \%(P<0.0001)(95 \%$ CI 4.8 to 8.4); female mortality decreased by $4.3 \%$ from $32.6 \%$ to $28 \cdot 3 \%(P<0.01)(95 \%$ CI 1.3 to $7 \cdot 4)$. Reductions in mortality occurred in all age and sex groups but were greater in younger patients. Logistic regression analysis of death rates showed that the odds ratio of death in 1991 compared with that in 1979 was $0.75(95 \%$ CI 0.69 to 0.82 ). After allowing for the effects of age and sex, this odds ratio became 0.54 (95\% CI 0.49 to 0.59$)$, as more elderly patients were treated in 1991. Purchase of streptokinase increased 31-fold from 116 doses in 1983 to 3554 doses in 1991. There was a pronounced negative association between annual purchases of streptokinase and mortality (Kendall's rank correlation $=-0.86, P=0.003)$. Changes in clinical practice resulted in the saving of the lives of an estimated 600 patients with acute myocardial infarction in 1991. This extrapolates to an annual saving of 10500 lives in the United Kingdom.
\end{abstract}

Conclusions-In the past few years thrombolytic treatment has been widely adopted for the management of acute myocardial infarction. This has been paralleled by a substantial reduction in inhospital mortality.

(Br Heart f 1995;74:493-496)

Keywords: thrombolytic treatment, acute myocardial infarction, in-hospital mortality, streptokinase.

^Now North Thames (West)
Clinical trials were published in the mid-late 1980s showing potential reductions of inhospital mortality of up to $40 \%$ with thrombolytic treatment. ${ }^{1-3}$ Before these, patients with acute myocardial infarction were admitted to a cardiac care unit and monitored. Treatment was directed at complications such as malignant ventricular arrhythmia or cardiac failure. By the late $1980 \mathrm{~s}$, in response to the trial data, a variety of pharmacological agents, particularly thrombolytic and antiplatelet drugs, were being routinely administered to these patients. $\beta$ blockers and nitrates were used to a lesser extent. ${ }^{4}$ It is important to investigate the extent to which benefits shown in clinical trails are realised in routine clinical practice. ${ }^{5} \mathrm{We}$ aimed to assess the impact of these changes in clinical practice on mortality.

\section{Patients and methods}

This study was a retrospective analysis of data from all the health service hospitals of the North West Thames health region. This region serves a resident population of 3486900 in an area to the north and west of central London. It contains 13 health districts and 21 major hospitals. Information was obtained on the numbers of deaths and deaths plus discharges for all age groups and all hospitals for the years 1979-1991. For the purposes of the study it was assumed that the sum of deaths and discharges equalled the number of admissions. The information related to all patients with a main diagnosis of International Classification of Diseases, with revision, code 410-acute myocardial infarction. The data were entered into a central computer database. Reliable information was not available for 1987 because of implementation of a new regional database, therefore that year was excluded from consideration.

Information was obtained from the regional pharmaceutical database concerning the purchase of streptokinase to estimate the use of thrombolytic treatment in the region in the years 1983-1991. These data refer to numbers of doses $(1.5 \mathrm{MU})$ purchased. Given the reluctance of pharmacists to hold large stocks of streptokinase for long periods of time we consider that the purchase data reflect actual use.

STATISTICAL METHODS

To assess the overall reduction in mortality 
Figure 1 Male, female, and total absolute mortality from acute myocardial infarction 1979-1991.

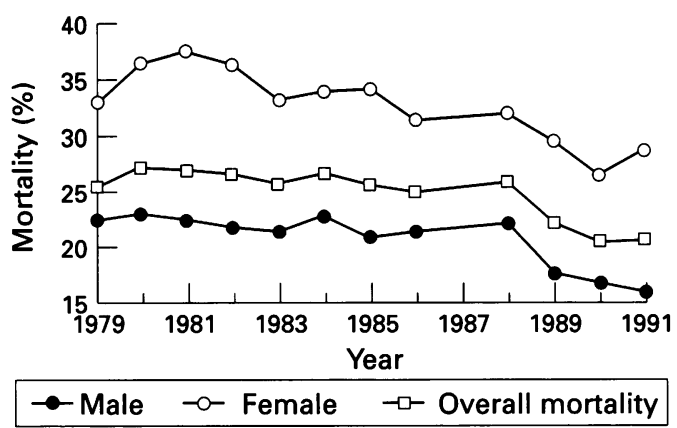

over the period, logistic regression analysis was used, ${ }^{6}$ including a factor of 12 levels which represented the year in which the myocardial infarction took place (one for each year from 1979 to 1991, excluding 1987). Thus the odds ratio for death in 1991 compared with that in 1979 could be estimated. In addition, the effects of age (six groups) and sex were allowed for in estimating the odds ratio, as more elderly patients were included later in the study period. The $95 \%$ confidence intervals $(95 \% \mathrm{CI})$ for these odds ratios were also calculated. $^{7}$

The crude odds of dying in 1991 were calculated from data for that year, and divided by the odds ratio for death in 1991 compared with that in 1979. This was an odds ratio adjusted for age and sex and thus gave the odds of death in 1979 if the age sex distribution had been the same as in 1991. Converting this 1979 "odds" to a 1979 "probability" of death allowed us to multiply by the number of admissions in 1991 and estimate the expected number of deaths that would have occurred in 1991 if the age sex-specific death rates for 1979 had applied. The difference between the expected and observed deaths for 1991 gives the number of lives saved.

\section{Results}

Between 1979 and 1991, during the 12 years for which we have data, there were 63903 admissions with acute myocardial infarction in the North West Thames health region. There were 41702 men $(65.3 \%)$ (mean (SD) age $64 \cdot 2(12 \cdot 3)$ years) and 22201 women $(34 \cdot 7 \%)$ (mean (SD) age $72.7(11.5)$ years). Overall mortality has decreased from $25.4 \%$ in 1979 to $20.2 \%$ in 1991 ( $P<0.0001$ ) (fig 1 ), and reductions occurred for patients in every age and sex group (figs $2(\mathrm{~A})$ and $2(\mathrm{~B})$ ). The relative reduction was greater in younger age groups.

Figure 2 (A) Male and (B) female absolute mortality from acute myocardial infarction by age 1979-1991.

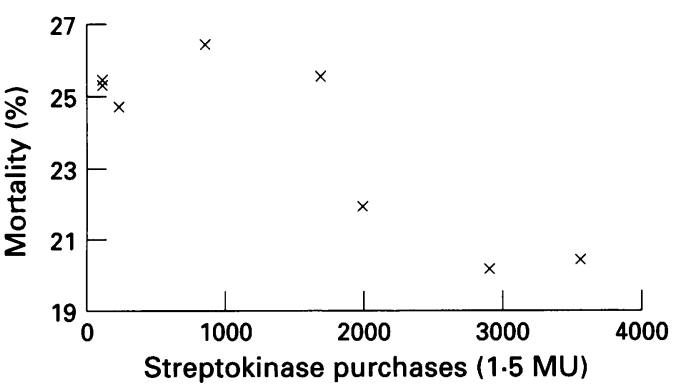

Figure 3 Relation between annual purchase of streptokinase and mortality.

A logistic regression analysis that compared mortality in the 12 separate years of the study revealed an odds ratio of 0.75 for death in 1991 compared with that in 1979 (95\% CI 0.69 to 0.82 ). Allowing for the effects of age and sex reduced this odds ratio to 0.54 (95\% CI 0.49 to 0.59$)$. As more elderly patients were treated later in the study period, the adjusted value gives a better estimate of the true reduction.

Applying this adjusted odds ratio to the crude mortality of $20.2 \%$ in 1991 gives a mortality of $31.87 \%$ in 1979 if the age sex distribution of 1991 had applied. Thus of 5222 people treated in 1991, 1664 deaths would be expected on the basis of 1979 death rates, as opposed to the 1064 observed; thus 600 lives were "saved". If these values are extrapolated nationally we estimate that in Great Britain and Northern Ireland about 10500 lives are being saved annually.

The purchase of streptokinase has increased 31-fold from 116 doses in 1983 to 3554 doses in 1991. Figure 3 shows the negative association between annual purchases of streptokinase and mortality during the study period, (Kendall's rank correlation $=-0.86$, $\mathrm{P}=0.003$ )

\section{Discussion}

The 1980s saw the publication of clinical trials consistently showing the survival benefits of systemic thrombolysis in patients with acute myocardial infarction. The Gruppo Italiano per lo Studio della Streptochinasi nell'Infarto Miocardico- $1^{1}$ used streptokinase as active treatment; 21 day mortality was $10.7 \%$ compared with $13 \%$ in the untreated group, a reduction of $18 \%$. The Second International Study of Infarct Survival Collaborative Group (ISIS-2) ${ }^{2}$ demonstrated that treatment with streptokinase and aspirin reduced 5 week vascular mortality from $13.2 \%$ to $8 \%$, an odds reduction of $42 \%$.

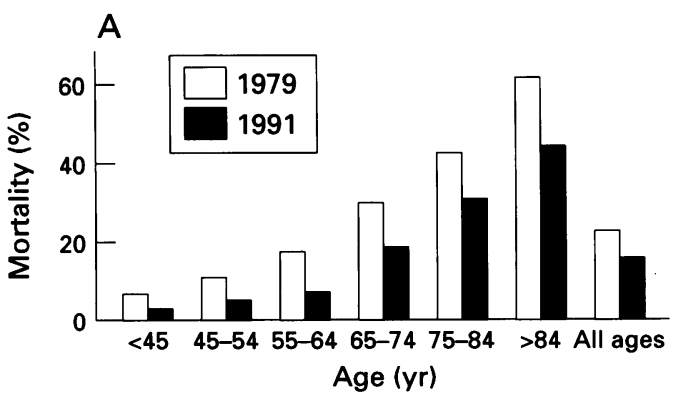


Similar benefits were found from the use of anistreplase in the AIMS (APSAC intervention mortality study) trial ${ }^{3}$ and recombinant tissue plasminogen activator (rt-PA) in study by Wilcox $e t a l^{8}$ (ASSET(Anglo-Scandinavian study of early thrombolysis)). The Gruppo Italiano per lo Studio della Sopravvivenza nell'Infarto Miocardico- $2^{9}$ and the International Study Group ${ }^{10}$ reported mortalities of about $8.8 \%$ in patients treated with alteplase (t-PA) or streptokinase with or without heparin. The Third International Study of Infarct Survival Collaborative Group ${ }^{11}$ directly compared streptokinase, tissue plasminogen activator (t-PA, duteplase), and anistreplase. The 35 day mortality with each of these regimens was virtually identical at approximately $10.5 \%$.

Placebo and treatment death rates in trials are considerably below the inhospital mortality of $25 \%$ previously reported in England and Wales. ${ }^{12}$ It is therefore likely that a degree of case selection occurs when patients are considered for trial entry and that high risk patients including the elderly are excluded. In 1979 mortality for the 75-84 and the $>84$ age groups were $44 \%$ and $57 \%$. Patients aged 75 years or over contribute about $40 \%$ of deaths but only about $20 \%$ of patients with acute myocardial infarction. They thus increase disproportionately the overall inhospital mortality.

Among patients less than 75 years we found that the percentage reduction in mortality was over $38 \%$, mirroring the percentage reductions observed in clinical trials. Older patients have shown substantial but relatively smaller reduction in mortality. This reduced level of benefit may in part be due to policies that restrict the use of thrombolytic treatment to patients below an arbitrary age, which can range from 65 to 80 years. ${ }^{13}$

In both sexes by 1991 there had been a significant decrease in mortality. Overall female mortality remains almost twice that in males. This is because females tend to present with myocardial infarction at an older age than males. Mortality for males and females of the same age group are little different. Further, the improvements in mortality seen in 1991 compared with those in 1979 are similar for males and females of the same age groups. The relative reduction in male mortality $(25.7 \%)$ was almost twice that in women $(13.3 \%)$, reflecting this age difference between the two populations.

Between 1987 and 1989 the percentage of physicians and cardiologists routinely using thrombolysis increased from $2 \%$ to $68 \%{ }^{4}$ At the same time $42 \%$ of consultants treated patients more than 70 years of age but only $8 \%$ treated those greater than 75 . Our data show the reduction in inpatient mortality from acute myocardial infarction which has paralleled this change in practice.

There are other possible explanations for the observed decrease in inhospital mortality. One would be a reduction in length of stay over the study period. There is little evidence to support this. The Nottingham Heart Attack
Register has reported that mean length of stay for patients with a definite myocardial infarction was 9.3 days in 1989 compared with 9.2 days in $1983 .{ }^{14}$ Studies such as the ISIS-2 clearly show that most deaths occur during the first 2 days after admission. ${ }^{2}$ Late hospital death is much less common thus reductions of length of stay would have produced only marginal reductions in the overall inhospital mortality. Although there may be limitations in the data we have reported, that is-routinely collected data on deaths and discharges, the data appeared consistent between hospitals and also the data from this region were in line year by year with the nationally collected data. ${ }^{15}$ We thus feel that it provides a useful measure of inhospital mortality trends during the period.

The use of $\beta$ blockers has also possibly contributed to the observed reduction in inhospital mortality. In the First International Study of Infarct Survival by the Collaborative Group atenolol was given to patients with suspected acute myocardial infarction at the time of admission. ${ }^{16}$ There was a small $(11 \%)$, but statistically significant reduction in overall vascular mortality at 1 year from $12 \%$ in the placebo group to $10.7 \%$ in those treated with atenolol. In this study mortality in the first week was $4.57 \%$ in the placebo group and $3.89 \%$ in the atenolol group. Two previous studies by the Norwegian Multicenter Study Group ${ }^{17}$ using timolol and the $\beta$ blocker Heart Attack Trial Research Group ${ }^{18}$ using propranolol had shown long-term prognostic benefit to patients given $\beta$ blockers after acute myocardial infarction.

These studies have had a lesser impact on practice than the trials of thrombolysis. In 1984 it was reported from a random sample of British consultant cardiologists that long-term $\beta$ blockade was used by only $34 \%$ to treat prophylactically "all patients who do not have a contraindication to beta blockade". 5 This seems to reflect the attitude of consultants generally. The British Heart Foundation survey ${ }^{4}$ found that in $198725 \%$ of consultants used oral $\beta$ blockers and $4 \%$ intravenous $\beta$ blockers "routinely for most patients" with acute myocardial infarction. By 1989 the corresponding values were $31 \%$ and $3 \%$. Our study shows no change in inhospital mortality several years after publication of these trials and before the reports showing benefit from thrombolysis. We cannot determine whether this is due to lack of widespread use of $\beta$ blockade or whether the benefits shown in the trials have failed to occur during the inhospital phase of acute myocardial infarction.

We conclude that the introduction of thrombolytic treatment in acute myocardial infarction has been paralleled by a substantial reduction in inhospital mortality. Further benefit could be obtained by more widespread use of such treatment and minimisation of delays in its initiation. Treatment should be given regardless of age. Further studies are needed to investigate the development of new or modified procedures enabling more rapid assessment and timely initiation of treatment of patients with acute myocardial infarction. 
We would like to express our gratitude to all the medical and non-medical staff at the hospitals in the North West Thames Health Region. Their work over many years has made this study possible. We would also like to thank the staf regional statistical and pharmacy departments for their help.

1 Gruppo Italiano per lo Studio della Streptochinas nell'Infarto Miocardico (GISSI). Effectiveness of intravenous thrombolytic treatment in acute myocardial infarction. Lancet 1986;i:397-402.

2 ISIS-2 (Second International Study of Infarct Survival) Collaborative Group. Randomised trial of intravenous streptokinase, oral aspirin, both, or neither among 17187 cases of suspected acute myocardial infarction: ISIS-2. Lancet 1988;ii:349-60.

3 AIMS Trial Study Group. Effect of intravenous APSAC on mortality after acute myocardial infarction: preliminary report of a placebo-controlled clinical trial. Lancet 1988; report of a

4 Collins $R$, Julian D. British Heart Foundation surveys (1987 and 1989) of United Kingdom treatment policies for acute myocardial infarction. $B r$ Heart $\mathcal{f} 1991 ; 66$ : $250-5$.

5 Colling A. $\beta$ blockers after myocardial infarction; have trials changed practice? $B M F$ 1985;290:322.

6 Cox DR. Analysis of binary data. London: Methuen, 1970.

7 Gardner MJ, Altman DG. Calculating confidence intervals for proportions and their differences. In: Gardner MJ, for proportions and their differences. In: Gardner Altman DG, eds. Statistics with confidence-confidence
intervals and statistical guidelines, London: British Medical intervals and statist

8 Wilcox RG, von der Lippe G, Olsson CG, Jensen G, Skene AM, Hampton JR. Trial of tissue plasminogen activator for mortality reduction in acute myocardial infarction (ASSET). Lancet 1988;ii:525-30.
9 Gruppo Italiano per lo Studio della Sopravvivenza nell'Infarto Miocardico (GISSI). GISSI-2: a factorial randomised trial of alteplase versus streptokinase and heparin versus no heparin amongst 12490 patients with acute myocardial infarction. Lancet 1990;336:65-71.

10 The International Study Group. In-hospital mortality and clinical course of 20891 patients with suspected acute myocardial infarction randomised between alteplase and myocardial infarction randomised between alteplase and strepto

11 ISIS-3: a randomised comparison of streptokinase vs tissue plasminogen activator vs anistreplase and of aspirin plus heparin vs aspirin alone among 41299 cases of suspected acute myocardial infarction: ISIS-3. Lancet 1992;339: 753-70.

12 Greenbaum RA. Routine use of beta-blockers following myocardial infarction: a note of dissent. $\mathcal{F} R$ Soc $M e d$ 1987;80:402-3.

13 Burrell CJ, Skehan JD, Cowley ML, Barrett CW, Mills PG. Districts' use of thrombolytic agents. $B M F$ f 1990;300: 237-8.

14 Hampton P, Harrison L, Grey D. Demand for hospital services following admission with suspected myocardial infarction in 1983 and 1989. Health Trends 1993;25: 91-4.

15 Office of Population Censuses and Surveys. 1991 Mortality statistics cause. London: HMSO, 1993.

16 ISIS-1 (First International Study of Infarct Survival) Collaborative Group. Randomised trial of intravenous atenolol among 16027 cases of suspected acute myocardial infarction: ISIS-1. Lancet 1986;ii:57-65.

17 The Norwegian Multicenter Study Group. Timololinduced reduction in mortality and reinfarction in induced reduction in mortality and reinfarction in patients surviving acure

18 Beta-blocker Heart Attack Trial Research Group. A randomized trial of propranolol in patients with acute myocardial infarction. $\mathfrak{f} A M A 1982 ; 247: 1707-14$. 